Nevşehir Bilim ve Teknoloji Dergisi TARGíd Özel Sayı 280-285 2016

DOI: 10.17100/nevbiltek.211010

URL: http://dx.doi.org/10.17100/nevbiltek.211010

\title{
6360 Sayılı Büyükşehir Yasasının Kırsal Kesime Olası Etkileri
}

\author{
Merve Ayyıldı*, Adnan Çiçek, Bekir Ayyıldız \\ Gaziosmanpaşa Üniversitesi, Ziraat Fakültesi, Tarım Ekonomisi Bölümü, Tokat
}

Öz

Büyükşehir yasası ile 2014 tarihinden sonra Türkiye'de yeni bir idari yapılanma sürecine girilmiştir. Kırsal kesime hizmet eden il özel idareleri kaldırılmış, bu görev il mülki sınırları içerisinde büyükşehir belediyelerine verilmiştir. Bunun bir sonucu olarak 30 ilde 16561 köyün tüzel kişiliği kaldırılarak mahalle statüsüne dönüştürülmüştür. Köy yerleşim yerlerine kamu hizmetinin getirilmesi büyükşehir ve ilçe belediyelerinin yükünü artırmış ve yeterli hizmetin sağlanamayacağı endişesini doğurmuştur. Aynı zamanda büyükşehir ve ilçe belediyelerine tarım ve hayvancıllğı desteklemek amacıyla her türlü faaliyet ve hizmet yetkisi verilmiştir. Bu yeni durumun kırsal kesimi ve tarım sektörünü nasıl etkileyeceği bilinmemektedir. Bu çalışmada, Türkiye'nin \%52'sinde gerçekleşen idari yapı değişiminin kırsal kesime ve özellikle tarıma etkileri belirlenmeye çalışılmış ve ne gibi önlemler alınabileceği tartışılmışır.

Anahtar Kelimeler: Büyükşehir Yasası, Tarım, Kırsal Alan

\section{The Rural Area Potential Impact of Metropolitan Law No. 6360}

\begin{abstract}
Abtract
Turkey has started a new administration restructuring with "Metropolitan Municipolity Low" after 2014. Special provincial administration abolihed from serving rural area and this task was given to metropolitan municipolities in the disstrict provinces. As the result of this case 16561 villages legal entity abolished and can verted into neigborhod in 30 provinces. The introduction of public services to village settlement brings increased burdan of metropolitan and district municipolities and it has led to concern of not providing adequate services. As well as metropolitan and district munipolities were given the authority to support agriculture and animal husbandory services. This new status is unknow how to it will affect agriculture and rural areas. This study aims to take precautions to identify the effect of verted the administrative structure for $\% 52$ of Turkey.
\end{abstract}

Keywords: Metropolitan Law, Agriculture, Rural Area

*e-mail: m.ayyildiz@outlook.com 


\section{Giriș}

Türkiye'de kentsel ve kırsal kesimlerin yönetilmesi ve bu kesimlere yönelik yürütülecek hizmetlere ilişkin sistem arayışları cumhuriyetin ilanından bugüne kadar devam etmektedir. Özellikle kentsel nüfustaki artışlar bu arayışları zorunlu hale getirmiştir. 1982 Anayasasının 127. Maddesi ile il, belediye ve köylere tüzel kişilik verilmiştir [1]. Bu yasa aynı zamanda büyük yerleşim yerleri için, özel yönetim biçimleri oluşturulabilmesine imkan tanımıştır. Bu hükme paralel olarak büyükş̧ehir belediyeleri ile ilgili ilk düzenleme 1984 yılında yürürlüğe giren 3030 sayılı Büyükşehir Belediye Kanunu ile gerçekleştirilmiştir. Bu yasanın çıktığı dönemde İzmir, İstanbul ve Ankara illerinin belediyeleri büyükşehir belediyelerine dönüştürülmüştür . Devam eden yıllarda Adana (1986), Bursa, Gaziantep, Konya (1987), Kayseri (1988), Antalya, Diyarbakır, Eskişehir, Erzurum, Mersin, Kocaeli, Samsun (1993) ve Adapazarı (2000) büyükşehir statüsü kazanarak büyükşehir belediye sayısı 16'ya ulaşmıştır.

$\mathrm{Bu}$ şehirlerin büyükşehir statüsü kazanmasındaki en önemli etken nüfus büyüklükleridir ve dolayısıyla kentte yaşam ve hizmet kalitesinin arttırılması amaçlanmıştır. 1930- 2004 yılları arasında yürürlükte kalan 1580 sayılı Belediye Kanunu hiçbir ayrım gözetmeksizin tüm il belediyelerine eşit mesafeden bakmayı ön görmekteyken 5216 sayılı yasa ile birlikte coğrafi ölçüm ve nüfus şartı getirilerek büyükşehirlerin sınırları ve görev alanları genişletilmiştir. Bu yasa "pergel" düzenlemesi ismiyle bir yöntem getirmiş ve illerdeki valilik binaları merkez kabul edilerek nüfusu bir milyona kadar olan illerde yarıçap $20 \mathrm{~km}, 1-2$ milyon arasındaki illerde $30 \mathrm{~km}$ ve 2 milyondan fazla olan illerde ise $50 \mathrm{~km}$ yarıçap sınırı, büyükşehir belediye sınırı olarak belirlenmiştir. Ayrıca İstanbul ve Kocaeli’nde büyükşehir belediye sınırları il idari sınırı olarak kabul edilmiş̧ir [2]. Bu yasa ile aslında büyükşehir sınırlarının giderek il mülki sınırlarını da içine alacak şekilde yapılanmasının temelleri de atılmıştır. Bir yandan büyük yerleşim yerlerine ilişkin gelecekte daha iyi imar planı oluşturmasına imkan sağlanmışken öte yandan bu yerleşim yerlerine bağlı köy ve belde gibi kırsal yerleşim birimlerinin ve tarımsal üretim merkezlerinin etkilenmeye başladığı ifade edilebilir.

2004 y1lında İstanbul ve Kocaeli’nde başlayan pilot uygulama, 2012 yılında kabul edilen ve 2014 yerel seçimleri ile yürürlüğe giren 6360 sayılı yasa ile Türkiye'nin büyük bir kısmını kapsayacak şekilde genişletilmiştir. Bu yasayla birlikte Aydın, Balıkesir, Denizli, Hatay, Malatya, Manisa, Kahramanmaraş, Mardin, Muğla, Tekirdağ, Trabzon, Şanlıurfa ve Van illeri büyükşehir belediyelerine dönüştürülmüştür. Böylece Türkiye'deki büyükşehir sayısı 30'a yükselmiş (2013 yılında çıkarılan 6447 sayılı yasa ile Ordu ili dahil) ve köy ile beldelerin idari yapısında köklü değişiklikler yapılmıştır. Toplam 16.561 köy mahalle statatüsü kazanarak tüzel kişilikleri kaldırılmıştır [3].

Kocaeli ve İstanbul' da toplam nüfusun büyük bir çoğunluğu kentsel nüfustan oluşmaktadır. 2012 yılı verilerine göre İstanbul'da kentsel nüfus oranı \%98,9, Kocaeli'nde ise \%93,4'tür . Ancak 2012 yılından itibaren büyükşehir statüsü kazanan iller kentsel nüfus kadar kırsal nüfusa da sahiptirler. Örneğin Hatay \%49,95'lik, Van \%47,84'lük, Ordu \%42,90’lık kırsal alana sahip illerdir [4]. Sonuç olarak özellikle 30 Mart 2014 tarihinden itibaren Türkiye'de farklı ve yeni bir uygulama başlamıştır. Özellikle kırsal alanda köy tüzel kişiliklerinin kaldırılması, hizmetlerin ilçe ve büyükşehir belediyelerince yürütülecek olması, köy ortak kullanım alanlarının mülkiyetinin değişimi gibi birçok yeni uygulama söz konusudur [5]. Bu uygulamaların ne gibi sonuçlar doğurduğunu ve doğuracağını bilmek sağlıklı bir kırsal kalkınma açısından önemlidir [6]. 


\section{Materyal ve Metot}

Çalışmanın ana materyalini Gıda Tarım ve Hayvancılık Bakanlığı’nın desteği ile yürütülmekte olan bir projenin saha çalışmalarından elde edilen birincil veriler oluşturmaktadır. Ayrıca, konu ile ilgili yerli literatür ve Türkiye İstatistik Kurumunun verilerinden sağlanan ikincil veri kaynaklarından yararlanılmıştır.

Çalışmada, 6360 sayılı büyükşehir yasasının kırsal alana olası etkileri, avantajlar ve dezavantajlar perspektifinden bakılarak yorumlanmaya çalışılacaktır.

\section{Bulgular}

\subsection{Büyükşehir Yasasının Kırsal Kesime Sağlayacağı Avantajlar}

Ülkelerin sosyal ve ekonomik gelişimi açısından kurum ve kuruluşların üstlendiği belirli görevler bulunmaktadır. Mahalli idareler ve özelde belediyeler, gelişmişlik ve kalkınmışlı̆ga ilişkin birçok hizmeti ülke vatandaşlarına ulaştırmak yükümlülüğündedirler. Belediye hudutları içersinde imar ile ilgili düzenlemeler, içme suyu, kanalizasyon, su ve atık su arıtma, itfaiye hizmetleri, çöplerin toplanması, zabıta hizmetleri, daha iyi bir yaşam alanı oluşturulması, çevre ile ilgili yatırımlar bu yükümlülükler arasında yer almaktadır.

1982 anayasası ile gündeme gelen belediyecilik olgusu geçen 33 yılın ardından Türkiye'nin yaklaşık \%93'üne hizmet vermekte olan bir yapıya kavuşmuştur. Bu süreç içersinde belediyelerin önemli tecrübeler edindiği yadsınamaz. Belediyelerim, yol yapımı çalışmaları, içme suyu temini, içme suyu hatlarının döşenmesi, kanalizasyon ve atık su hatları, çocuk oyun bahçeleri, spor tesisleri vs. birçok faaliyette uzmanlaştığı söylenebilir.

6360 sayılı yasa ile birlikte 16.561köyün tüzel kişiliği kaldırılarak belediyelere bağlı mahalle haline gelmiştir. Bu yasa öncesi köylere ilişkin temel hizmetler köy bütçesi ve il özel idaresinin destekleri ile sağlanmaktaydı. Bu bağlamda, köy bütçesindeki yetersizlikler ve il özel idarelerinin yetki ve sorumluluklarının oldukça fazla oluşu sebebiyle temel hizmetler tam anlamı ile karşılanamamaktaydı. Temel hizmetler kapsamında değerlendirilen bu faaliyetlerin belediyeler tarafindan gerçekleştirilecek olması kırsal alandaki yaşam şartlarının iyileştirilmesi açısından önemli görülmektedir.

Ayrıca, kırsal yerleşim yerlerinde sağlıklı yapılaşmanın ve afet riski olan yapıların denetiminin olmayışı birçok problemi beraberinde getirmekteydi. Belediyelerin bu yönlü bir hizmeti üstlenecek olması planlı yapılaşma için önem arz etmektedir. Öte yandan, il idari sınırları içersinde taşımacılık sistemlerinin tek elden ve belediyeler aracıllğı ile kontrol edilecek olması, kırsal nüfusa ulaşım konusunda birçok kolaylık sağlayacağı düşünülmektedir.

\subsection{Büyükşehir Yasasının Kırsal Kesime Getireceği Dezavantajlar}

\subsubsection{Temel Hizmetler ve Mali Yükümlülükler Açısından Etkileri}

Türkiye'de coğrafi yapı gereği kırsal yerleşim alanları ile kentsel yerleşim alanları arasındaki uzaklık azımsanamayacak ölçüde fazladır. 6360 sayılı yasanın uygulanmaya başlandığı illerin büyük bir çoğunluğu (İstanbul ve Kocaeli illeri hariç olmak üzere) yerleşim açısından dağınık bir yapı içersindedir. $\mathrm{Bu}$ bağlamda, belediyelerce yürütülecek hizmetlerin kırsal alana ulaştırılması hususunda endişeler 
mevcuttur. Özellikle 6360 sayılı yasada belirtildiği gibi su, kanalizasyon ve itfaiye hizmetlerinin büyükşehir belediyeleri tarafından yürütülecek olmasının yetersiz kalacağını düşündürmektedir.

Yasa ile birlikte belediyelerin hizmet götüreceği alan genişletilmiştir. Belediyelerin, kent merkezlerinden uzaklaşıldıkça yerleşim birimlerine götüreceği hizmet kalitesinin azalabileceği kaçınılmaz görünmektedir. Öte yandan, köy bütçesinin kaldırılması köylü devlet işbirliği ile yapılacak çalışmaların etkinliğini azaltacaktır. Geçmiş yıllarda il özel idaresi katkısıyla veya proje bazında köylü devlet işbirliği ile sağlık ocağı ve okul yapımı, içme suyu hatlarının döşenmesi vb. birçok çalışma yürütülmüştür. Bu çalışmalarda köy bütçesi önemli misyon üstlenmiştir. Nitekim il özel idareleri, il genel meclisi kararı ile nakdi ve ayni olarak köy bütçesine katkı sağlamışlardır. Büyükşehir yasası ile birlikte köylerde yapılacak olan birçok hizmetin ya belediye personeli aracılığıyla ya da taşeron firmalara ihalesi ile mümkün olabilecektir. Bu doğrultuda, köy bütçesi olmaksızın salt belediyelerin getireceği hizmet kısa vadede yetersiz kalacaktır.

Mali açıdan zayıf durumdaki ilçe belediyelerinin köy yerleşim yerlerine belediye hizmetlerini götürmeleri ayrı bir endişe oluşturmaktadır. Çünkü nüfusu az olan birçok ilçe belediyesi mali olarak zayıf ve borçlu durumdadır. Dolayısıyla bu belediyelerin hizmet önceliği ilçe merkezindeki mahalleler olacaktır. Bu durum ilçe merkezine uzak olan köy yerleşimlerinin belediyecilik hizmeti açısından ihmal edileceği anlamına gelmektedir.

6360 sayılı yasa ile birlikte köy tüzel kişilikleri yanı sıra çok sayıda belde belediyesi kaldırılmış ve söz konusu beldeler belediyelere bağlı mahalle konumuna getirilmiştir. Beldelere ait taşınır ve taşınmaz varlıklar, büyükşehir sınırları içersinde ilçe belediyelerine devredilmiştir. $\mathrm{Bu}$ durumda, hizmetlerin götürüleceği endişesine ek olarak hizmetlerin ne zaman ulaştırılacağı endişesi de doğmaktadır.

Kırsal nüfusun, temel hizmetlerinin karşılanamayacağına ilişkin bir takım endişelerin yanı sıra mali yükümlülüklerinin artacağı bilinmektedir. Bu doğrultuda kırsal alanda yaşamaya ilişkin itici güçlerin ortaya çıkacağı düşünülmektedir. Su ve atık su ücretleri, emlak vergisi, yapılacak inşaatlara ilişkin proje masrafları ve diğer mali yükümlülükler bunlardan bazılarıdır. Yasa çerçevesinde bu tür mali yükümlüklerin belirli bir zaman sürecinde yansıtılacağı belirtilmektedir. Ancak bu tür maliyetlerin gelir düzeyi düşük olan kırsal nüfusun yaşam standartlarını zorlayacağı düşünülmektedir.

\subsubsection{Tarımsal Hizmetler Açısından Etkileri}

Köy tüzel kişiliğine ait mera, yaylak, otlak vb. hayvancılık ile ilgili araziler büyükşehir belediyelerinin mülkiyetine geçmiştir. Yasa, söz konusu alanların kullanım haklarının köyde yaşayanlara ve diğer hak sahiplerine ait olduğunu vurgulamaktadır. Ancak gelecek yıllarda bu tür arazilerin kiralanma ya da satış durumlarının olması, köy yerleşim yerlerinde hayvancıllı̆ın etkinliğinin azalmasına yol açabilir.

Öte yandan bazı bölgelerde tarımsal alanların imara açılma riski söz konusudur. Her ne kadar tarımsal arazilerin imara açılmasında belediye meclis kararı ve Toprak Koruma Kurulu izni gerekiyor olsa bile, konut, ticaret, sanayi alanı, kamu yatırım alanı gibi amaçlarla tarımsal arazilerin imara açılma riski bulunmaktadır. 
Tarımsal sulama yatırımlarının (sulama kanalı, sulama göletti sistemleri vb.) kısa ve orta vadede etkilenmesi söz konusudur. Geçmiş yıllarda köy hizmetleri ve il özel idareleri tarafindan yapılan bu tür yatırımların belediye önceliğinde olmadığı söylenebilir. Aynı şekilde arazi toplulaştırma çalışmalarının olumsuz etkilenmesi söz konusudur.

Sabit hayvancılık yatırımları ( ahır, ağıl, samanlık, depo, hangar vs.) için proje ve imar izni gerekeceğinden hayvancılığın olumsuz etkilenmesi söz konusudur. Ayrıca çevre duyarlılığı nedeniyle köy yerleşim alanlarında bulunan ahırların köy dışına çıkartılacak olması hayvancılık faaliyetleri için endişe oluşturmaktadır. Her ne kadar 6360 sayılı yasa mevcut hayvancılık yapılarına imar müsaadesi verse bile zaman içerisinde ilave yasalarla bu durum sorun olabilecektir.

Büyükşehir yasasının 7. Maddesinin f bendinde "Büyükşehir ve ilçe belediyeleri tarım ve hayvancılık destekleri için her türlü faaliyette bulunabilirler" denilmektedir. Büyükşehir yasasında kırsal kesimdeki tarımsal hizmetlere yönelik en önemli maddenin bu olduğu söylenebilir. Yasanın uygulandığ tarihten önce kırsal kesimde tarımsal hizmetlere yönelik İl Özel İdaresi'nin çeşitli politika ve destekleri söz konusu olmaktaydı. Buna bağlı olarak geçmiş yıllarda Köy Hizmetleri İl Müdürlüklerinin yapılanma biçimi ve hizmet politikaları ağırlıklı olarak kırsal kesimin kalkındırılması ve tarımsal faaliyetlerin gerçekleştirilmesine yönelikti. Aynı anlayış köy hizmetleri kurumu kaldırıldıktan sonra İl Özel İdareleri' nde de devam etmiştir. Ancak 6360 sayılı yasa gereği bu görevi yerine getirmesi gereken Büyükşehir ve ilçe belediyelerinin tarımsal hizmetlere ilişkin bir alt yapısı bulunmamaktadır. Bu bağlamda, tarımsal hizmetlere ilişkin boşluğun doldurulmasının ve tarımsal kalkınmada birçok probleminin çözümünün uzun vadede mümkün olabileceği düşünülmektedir.

\section{Tartışma ve Sonuç}

Büyükşehir yasasının birçok alanda kırsal kesim üzerinde etkisi olduğu tartışılmaz bir durumdur. $\mathrm{Bu}$ bağlamda, kırsal alanda temel hizmetlerin belediyeler tarafindan yürütülecek olması kırsal nüfusun daha kaliteli hizmet alabileceğini ortaya koymaktadır. Ancak belediyelerin kırsal yerleşim bölgelerine uzaklıkları hizmetin ulaşımı açısından endişe oluşturmaktadır. Bu sebeple, büyükşehir ve ilçe belediyelerinde norm kadroda kırsal alana ilişkin zorunlu birimler oluşturulmalı ve bu birimlere ilişkin bütçe ayrımı gerekli görülmektedir.

Tarımsal hizmetlere ilişkin belediyelerin herhangi bir deneyiminin olmadı̆̆ Belediyelerin bu konuya ilişkin yapısal olarak düzenleme yapmaları zorunludur. Yapısal dönüşümlerin yanı sıra hayvancılık ve tarımsal faaliyetlere ile ilgili yasal düzenlemelerin gerekliliği şarttır.

Köy tüzel kişiliğine ait olan mera, çayır, tarla gibi alanların belediyelerin yetkisi ile satılması ya da kiralanması, köy yerleşim yerlerindeki hayvancılık faaliyetlerini olumsuz yönde etkileyeceğinden dolayı yasal düzenlemelerle hayvancıkla uğraşanların haklarının korunması şarttır. Ayrıca imar planlarına ilişkin düzenlemelerin, hayvancılık yatırımlarına engel olmayacak şekilde yapılmasının gerekliliğinin yanı sıra, mevcut hayvancılık yatırım haklarının korunmasına önem verilmelidir. İmar planlaması dışında hayvancılık faaliyetlerine ilişkin diğer bir husus, hayvancılık yapıları için belediyeler tarafindan uygulanacak imar ile ilgili ödemelere düşük tarife uygulanması ve ziraat bankasının bu yönlü yatırımlar ile ilgili kredi sağlamasında imar ile ilgili problemlerin (müşterek tapu) idari yollardan çözüme kavuşturulması hayvancılık faaliyetlerinin etkinliği açısından önemli görülmektedir. 
6360 sayılı Büyükşehir Yasasının uygulamaya konulmasından beş yıl sonra kırsal alanda yaşayanlara su ücreti, emlak vergisi, çevre temizlik vergisi vs. yükümlülüklerin getirileceği bilinmektedir. $\mathrm{Bu}$ tür yükümlülüklerin, kırsalda yaşamanın çekici gücünü azaltacağı yadsınamazdır. Bu doğrultuda, kırsal nüfusu yerinde tutacak politikalar izlenmesi ve yıllara sari uygulamaların öncelik olarak benimsenmesi önem taşımaktadır.

Köy tüzel kişiliğine ait olan alanlar dışında hazine ya da tescil dışı arazilerde köy halkının tarımsal faaliyetlerde bulunduğu bilinmektedir. Tarımsal faaliyetler açısından önemli olan bu arazilerin belediyelerin mülkiyetine geçmesi durumu kırsal nüfus üzerinde mali bir baskı yaratacağından dolayı yasal ve idari tedbirler ile tarımcıların hakları gözetilmek durumundadır.

\section{Kaynaklar}

[1] RG, Türkiye Cumhuriyeti Anayasası. Resmi Gazete Tarih: 9.11.1982. Sayı:17863, 1982.

[2] RG, Büyükşehir Belediyesi Kanunu. Resmi Gazete Tarih: 23.07.2004.Sayı: 25531, 2004.

[3] TÜIK, Yıllara ve Cinsiyete Göre İl/İlçe Merkezleri ve Belde/ Köy Nüfusu 1927- 2013. Avaiable from URL: http://www.tuik.gov.tr/preltatistikTablo.do?istab_id=1587, 2014, (23.03.2015).

[4] TÜIK, adrese dayalı nüfus kayıt sistemi sonuçları Available from URL: http://tuikapp.tuik.gov.tr/adnksdagitapp/adnks.zul., 2015, (23.03.2015).

[5] Gün, S., "Köylerin ve Kırsal Alanın Yeniden Tanımlanması Sürecinde Tarım Topraklarının Kullanımı ve Korunması" 11. Ulusal Tarım Ekonomisi Kongresi 3-5 Eylül, Samsun, 2014.

[6] Keleş, R., "anakent yönetimlerini düzenleyen yasa ne getirdi, ne götürüdü?” Available from URL: http://www.cekulvakfi.org.tr/makale/anakent-yonetimlerini-yeniden-duzenleyen-yasa-negetirdi-ne-goturdu , 2015, (12.03.2015). 